\title{
Temperature Change Implications for Flexible Pavement Performance and Life
}

\author{
Ahmed Ebrahim Abu El-Maaty \\ Faculty of Engineering, Minoufia University, Shibeen El-kom City, Egypt \\ Email address: \\ maaty5000@yahoo.com

\section{To cite this article:} \\ Ahmed Ebrahim Abu El-Maaty. Temperature Change Implications for Flexible Pavement Performance and Life. International Journal of \\ Transportation Engineering and Technology. Vol. 3, No. 1, 2017, pp. 1-11. doi: 10.11648/j.ijtet.20170301.11
}

Received: January 12, 2017; Accepted: January 20, 2017; Published: April 18, 2017

\begin{abstract}
The temperature of the asphalt concrete AC is one of the most important environmental factors that influences flexible pavement performance. The possibility hazard of temperature change raises attention in how it may affect the deterioration rates (deflection, strain and stress distributions) in flexible pavement and how pavement service life would be changed as a result. A change in the AC temperature directly influences the stiffness of the asphalt-bound layers, which modifies the stress statues inside the pavement. This alteration in stress can influence the stiffness of the underlying unbound layers since they generally show stress reliance. Due to these relations are nonlinear, the additional pavement life lost at higher than average temperature is not replaced by savings at lower than average temperature. For that, the deterioration amount are overvalues when average pavement temperatures are used for determining the asphalt stiffness. The objective of this research was to study the pavement temperatures throughout the year in Egypt on performance and life of seven pavement sections with different stiffness or thickness using mechanistic-empirical method to investigate the most influential characteristic under temperature change for improving the design of pavement structures. The results revealed the significance of the impact that climate change may have on the performance service life of flexible pavements. These changes may impact the pavement life cycle cost and thus their impact on future maintenance requirement should be investigated.
\end{abstract}

Keywords: Temperature Change, Flexible Pavement, Performance, Service Life, Stiffness, Layers Thickness

\section{Introduction}

Cumulative distresses, such as permanent deformation and fatigue cracking, practically define failure of the pavement surface layer. Excessive distresses lead to major defects, like potholes. Those distresses may result from many factors, e.g., improper choice of materials and respective proportions, excessive traffic loadings (more or heavier loads than anticipated in design), environmental effects (temperature and moisture conditions), aging of asphalt layers, among others. Therefore, pavement design methods need to take into account those factors in order to better predict the life of pavements, resulting in more reliable structures.

In designing durable pavements, many agents are considered and one such primary agent is the climate of the desired highway location that provides a significant influence on pavement performance. The most important climatic agent that significantly influences the mechanical behavior of all pavement layers and thus the overall performance and life of the pavement is temperature [1,2 and 3].

Asphalt mixtures are viscoelastic plastic materials where the strength and modulus of these materials clearly change under different temperatures. Thus, the choice of asphalt binder is closely related to the local temperature conditions to satisfy structural and functional requirements. For instance, at low temperatures, asphalt becomes hard and brittle and the asphalt layers are exposed to thermal and fatigue cracking. On the contrary, at high temperatures, asphalt becomes soft and more viscous and thus it is more prone to rutting. Thus, the temperature effect on bearing capability, performance, damage and life of asphalt pavement cannot be ignored [4 and 5]. The variation in temperature directly influences the stiffness of the asphalt layers, which alters the stress, strain and deflection conditions through the pavement. This variation can influence the stiffness of the underlying unbound layers since they usually display stress, strain and deflection dependence [6].

Mechanistic-empirical pavement design methods for flexible pavements usually assume two failure mechanisms 
attached to the design of the pavement cross section: fatigue of bound pavement layers and accumulated plastic deflections (rutting) in the subgrade. Pavement temperature is confirmed to have an effect on asphalt rutting, age hardening and thermal cracking or fatigue [7 and 8]. As a result of the visco-elastic nature of bituminous binders, temperature has an obvious function in the fatigue and rutting performance of flexible pavement. For example, more asphalt rutting is predicted under high temperatures, especially at high traffic volume and low speed. Flexible pavements expose to more age hardening under increased temperature. Age hardening is unwanted on the pavement surface, due to reducing the capability of pavement to flex under traffic. Due to age hardening, the asphalt surface becomes crisp and vulnerable to cracking. When pavements cool, cracking begins to increase due to thermal tensile stress [9 and 10].

\section{Literature Review}

Mainly, flexible pavement performance depend on pavement structure, applied load, pavement conditions and environmental factors, such as asphalt mix temperature and moisture content in unbound materials. The temperature of an asphalt mix is a determining factor of its performance. Asphalt mix properties change depending on temperature; thereby its response to traffic loads will also be different [11]. The bearing capacity and the performance of flexible pavement are clearly affected by variation of modulus of asphalt mixture which significantly affected by pavement temperature. Thus, temperature can influence the structural bearing capacity of flexible pavement in the following sides [12 and 13]:

1. The modulus of asphalt mixture reduces with increasing the pavement temperature thus the structural bearing capacity reduces.

2. Higher stress is transmitted to under layers according to the reduction of asphalt mixture modulus. However, material properties of base are relevant to stress level. Granular material of base course will be consolidated under the high stress level; however, cohesive soil will be more debility. Thence the temperature of asphalt mixture will straightway influences material properties of base and subbase.

3. Stress induced by temperature variation: according to microscopic mechanical model, in the case of temperature increase, the contact force among the granules of granular base will be bigger, leading to the increase of volume stress.

4. The increase of pavement temperature will decrease the pore water tension in upper layer. It can result in water in base transfers to upper layer which decreases pore water pressure. Effective stress of base or subgrade will be lower. Simultaneously, the modulus of material is reduced.

Previous researchers studied how to evaluate elastic modulus change of asphalt mixture under different temperatures because the asphalt mixture is viscoelastic plastic material thus its modulus varies with temperature [14]. American Asphalt Institute developed a function correlated between modulus of asphalt mixture and pavement temperature, physical properties of asphalt mixture, and load frequency, as following [15]:

$$
\begin{aligned}
& \log E=5.553833+0.028829 \frac{P_{200}}{f^{0.17033}}-0.03476\left(V_{v}\right)+0.070377\left(\eta_{70^{0} F, 10^{6}}\right) \\
& +0.000005\left(t_{P}^{(1.3+0.49825 \log f)} P_{a c}^{0.5}\right)-0.00189\left(t_{p}^{(1.3+0.49825 \log f)} \frac{P_{a c}^{0.5}}{f^{1.1}}\right) * 0.931757\left(\frac{1}{f^{0.02774}}\right)
\end{aligned}
$$

Where E: dynamic modulus of asphalt mixture;

P200: the passing rate of the aggregate in the No.200 sieve;

$\mathrm{F}$ : loading frequency;

$\mathrm{Vv}$ : porosity of mixture;

$\eta_{70^{0} F, 10^{6}}$ : absolute viscosity;

Pac: asphalt content;

tp: pavement temperature $\left({ }^{\circ} \mathrm{C}\right)$.

For generality, the temperature dependence of the asphalt was described as in AASHTO 1993[15].

$$
\log E=6.451235-0.000164671\left(\mathrm{t}^{1.92544}\right)
$$

where E: dynamic modulus of the asphalt concrete (psi); t: temperature of the asphalt $\left({ }^{\circ} \mathrm{F}\right)$.

Moreover, elastic modulus of asphalt layer can be determined as a function of pavement temperature according to the following equation [16]:

$$
\mathrm{E}=15000-7900 \log (\mathrm{t})
$$

where: E: dynamic modulus of the asphalt concrete $\left(\mathrm{N} / \mathrm{mm}^{2}\right)$; : pavement temperature $\left({ }^{\circ} \mathrm{C}\right)$.

Gang Zuo (2003) [3] concluded that the effect of $\mathrm{AC}$ temperature gradient was significant, especially when the AC layer is thin. The length of temperature averaging interval was shown to be most critical for pavement life estimation. Moreover, the estimated pavement life decreased as the length of the averaging interval decreased. Pavement designs based on monthly temperature average neglected the damage that occurs during brief periods of high temperature, leading to unconservative designs. The newly AASHTO released production version of the Mechanistic-Empirical Pavement Design Guide (MEPDG) which is called AASHTO ware pavement ME design was developed to overcome the limitations inherent in the AASHTO 1993 method. Breakah et al. (2011) [17] investigated the importance of accurate climatic data. They used built-in MEPDG climatic files and others developed based on historical information for counties in the state of Iowa to compare the pavement performance. They reported increased rutting for the northern part of the state, decreased thermal cracking, and decreased International Roughness Index (IRI) from climatic files that were inserted from the data available within MEDPG as compared to the developed historical climatic files.

Sascha et al. (2013) [4] illustrated that the fatigue damage 
estimated by adopting surface temperature combinations composed of a varying number of temperature intervals was more accurate than that estimated by adopting a single fixed temperature; the former was closer to the actual working conditions of pavement structures than the latter. Furthermore, the fatigue damage caused by a high temperature (or upper limit) of the representative value of the temperature intervals was larger than that caused by a low temperature (lower limit). Yaning et al. (2013) [8] reported that the temperature was the most influential climatic factor in the MEPDG for three investigated cases. Temperature (both an increase in the annual average temperature and the seasonal variation) had a significant impact on pavement distresses, including longitudinal cracking, fatigue cracking and (AC) rutting. Moreover, the pavement service life in the Virginia case was found to experience a dramatic reduction (greater than 20\%) due to a small $(5 \%)$ increase in temperature and temperature variation. This occurred when (AC) rutting became a critical distress for the pavement maintenance threshold.

\section{Research Objectives}

Roadways are key structures for the living and development of society since they are responsible for a large portion of the transportation of goods and people. Moreover, most of the highway system in Egypt is paved with asphalt materials, especially due to its low lifetime cost. In Egypt and many countries, the roadway system happens to be in bad conditions caused not only by the traffic loads but also by environmental conditions. In the case of asphalt pavements, temperature changes not only cause the material to expand/contract but also changes the material viscoelastic properties of asphalt mixtures. Unfortunately, most practitioners currently do not take into account either of these phenomena in the design of pavement structures. The objective of this research was to determine the variations in the predicted pavement damage ratio and life as well as the changes in pavement performance measured in terms of stress, strain and deflection distributions on the pavement surface and through layers due to temperature variation in Egypt using mechanistic-empirical method. Moreover, determining the most effective characteristic in pavement layers (stiffness or thickness) under various surface temperatures was achieved for improving the design of pavement structures.

\section{Research Methodology}

\subsection{Method of Data Analysis}

Currently many agencies in the U.S. and Canada as well as many countries in the world are trying to implement the pavement Mechanistic- Empirical (ME) design. However, one of the difficulties associated with its implementation is the amount and level of required inputs. In addition, the local calibration of the performance prediction models is another difficulty. The main advantage of ME method is that the analysis is based on pavement fatigue and rutting characteristics of all layers, rather than only on the pavement's surface performance (ride quality). Mechanistic empirical computer program such as KENPAVE can be used to run the calculation of the structural damage factors (stress, strain and deformation) of a flexible pavement. Thus, all the pavement reactions due to the temperature change can be determined more accurately, close to the actual condition 1 [18].

\subsection{Traffic Loading}

According to the Egyptian Code for urban and rural roads, traffic has been expressed in terms of repetitions of equivalent single-axle load (ESAL) with standard single axle load of $18000 \mathrm{Ib}$ of dual tires spacing 14 inch and standard tire pressure of 80 Psi [19]. The existing number of loading reputations is considered as 20000 yearly based field survey carried out at two rest- stations located on Cairo-Suez road and Cairo-Alexandria desert road [20].

\subsection{Pavement Failure Mechanisms}

Pavement failure occurs due to the environment, repeated traffic loading, and/or indigent maintenance strategies. Two failure mechanisms were taken into consideration in this study, coating the most dangerous load-associated pavement distresses fatigue cracking and subgrade rutting. Fatigue cracking caused by repeated axle load applications, generally lower than the material stiffness. It is a gradual damage because of the vacillating stresses and strains in the material and the accumulation of irreparable strains. Fatigue damage usually begins at the bottom of the asphalt layers, which symbolizes the area of the utmost tensile strain at completely bonded conditions between the different asphalt layers. Moreover, fatigue cracking can begin at the bottom of the individual asphalt layers in case of unbonded or friction conditions between the different asphalt layers. On another side, the subgrade rutting is a linear wheel path reduction that takes place when the subgrade displays plastic deflection or lateral migration because of loading effect. In such case, the pavement stabilizes into the subgrade ruts, causing surface reduction in the wheel path [21 and 22].

Several fatigue and rutting models have been developed to relate the asphalt modulus and/or the measured strains to the number of load repetitions to pavement failure. The fatigue and rutting models used in this study as shown in the following forms, is the one incorporated in the 9 th edition of the AASHTO design manual [15].

$$
\begin{gathered}
\mathrm{Nf}=0.0796(\varepsilon \mathrm{t})^{-3.291}(\mathrm{E} 1)^{-0.854} \\
\mathrm{Nr}=1.365 \times 10^{-9}(\varepsilon \mathrm{c})^{-4.477}
\end{gathered}
$$

Where: Nf: allowable number of load repetitions to prevent fatigue cracking from reaching a certain limit (10-20\% of the pavement surface area);

$\mathrm{Nr}$ : allowable number of load repetitions to prevent rutting from reaching a certain limit ( 0.5 inch);

$\varepsilon t$ : tensile strain on the bottom of the asphalt layer; $\varepsilon c$ : compressive vertical strain on the surface of subgrade; 
E1: elastic modulus of the asphalt layer (psi).

\subsection{Damage Prediction}

During the last few years excessive damages were observed on several highways. The reasons behind can be observed: mixture design, high temperature in summer, change in traffic load, etc. In the present study, the prediction of pavement life for fatigue and rutting is based on the cumulative damage concept in which a damage factor is defined as the damage per pass caused to a specific pavement system by the load in question. The incremental damage caused by each application of an $80-\mathrm{kN}$ (18-kip) equivalent single-axle load (ESAL) to a pavement with at temperature $i$ is as following [23]:

$$
\mathrm{Di}=1 / \mathrm{Ni}
$$

Where Di: is the cumulative damage factor and $\mathrm{Ni}$ is the minimum number of load repetitions required to cause either fatigue $(\mathrm{Nf})$ or rutting $(\mathrm{Nr})$ failure. The total number of load repetitions that are allowed over the pavement lifetime can be determined when total cumulative damage (Di) reaches one. Therefore, equations 4 and 5 can then be solved for the total allowable number of load applications required to cause either fatigue or rutting failures over the pavement life time.

\subsection{Pavement Cross Sections}

Materials in each layer are characterized by their stiffness (modulus of elasticity (E)) and a Poisson's ratio $(\mu)$.
In this research, effect of cross section characteristics (thickness and elasticity modulus of each layer) on performance and life of pavement was investigated under impact of temperature change. Thus, the optimal design factor that reduces the harmful effect of temperature change on pavement performance and life can be determined. For this purpose, seven cross sections varying from thinner section of higher stiffness to thicker section of lower stiffness were considered. Table1 shows the properties of the seven cross sections. Poisson's ratio was considered as $0.35,0.3,0.33$ and 0.4 for asphalt layer, base course, sub-base and subgrade respectively.

\subsection{Climatic Data Collection}

A total of 16 climatic data files covering the populated areas in different environmental conditions in Egypt were developed by Maha et al. (2014) [24] after collecting the historical climatic data from the original source; Egyptian meteorological authority. Figures 1 and 2 show a comparison of minimum, average, and maximum air temperature at the selected weather stations during the months of January and August, respectively in different cities distributed in all Egypt area. The monthly standard deviation of the air temperature is also shown on these Figures where the maximum and minimum air temperatures in Egypt during the summer and winter seasons were found to be about $47^{\circ} \mathrm{C}$ and $1{ }^{\circ} \mathrm{C}$ respectively.

Table 1. Properties of studied pavement cross sections.

\begin{tabular}{|c|c|c|c|c|c|c|c|}
\hline Section No. & 1 & 2 & 3 & 4 & 5 & 6 & 7 \\
\hline Surface thick. (in) & 2 & 2.5 & 3 & 3.5 & 4 & 5 & 6 \\
\hline E1 (psi) & \multicolumn{7}{|c|}{ As a function in temperature } \\
\hline Base thick. (in) & 5 & 5.5 & 6 & 6.5 & 7 & 8 & 9 \\
\hline E2 (psi) & $40 \mathrm{E} 3$ & $36 \mathrm{E} 3$ & $30 \mathrm{E} 3$ & $25 \mathrm{E} 3$ & 20E3 & $15 \mathrm{E} 3$ & $10 \mathrm{E} 3$ \\
\hline Subbase thick. (in) & 9 & 10 & 11 & 12 & 13 & 14 & 15 \\
\hline E3 (psi) & $15 \mathrm{E} 3$ & $13 \mathrm{E} 3$ & $12 \mathrm{E} 3$ & $10 \mathrm{E} 3$ & $9 \mathrm{E} 3$ & $8 \mathrm{E} 3$ & 7E3 \\
\hline Subgrade E4 (psi) & 7E3 & $6 \mathrm{E} 3$ & $5 \mathrm{E} 3$ & 4.5E3 & 4E3 & $3.5 \mathrm{E} 3$ & 3E3 \\
\hline
\end{tabular}

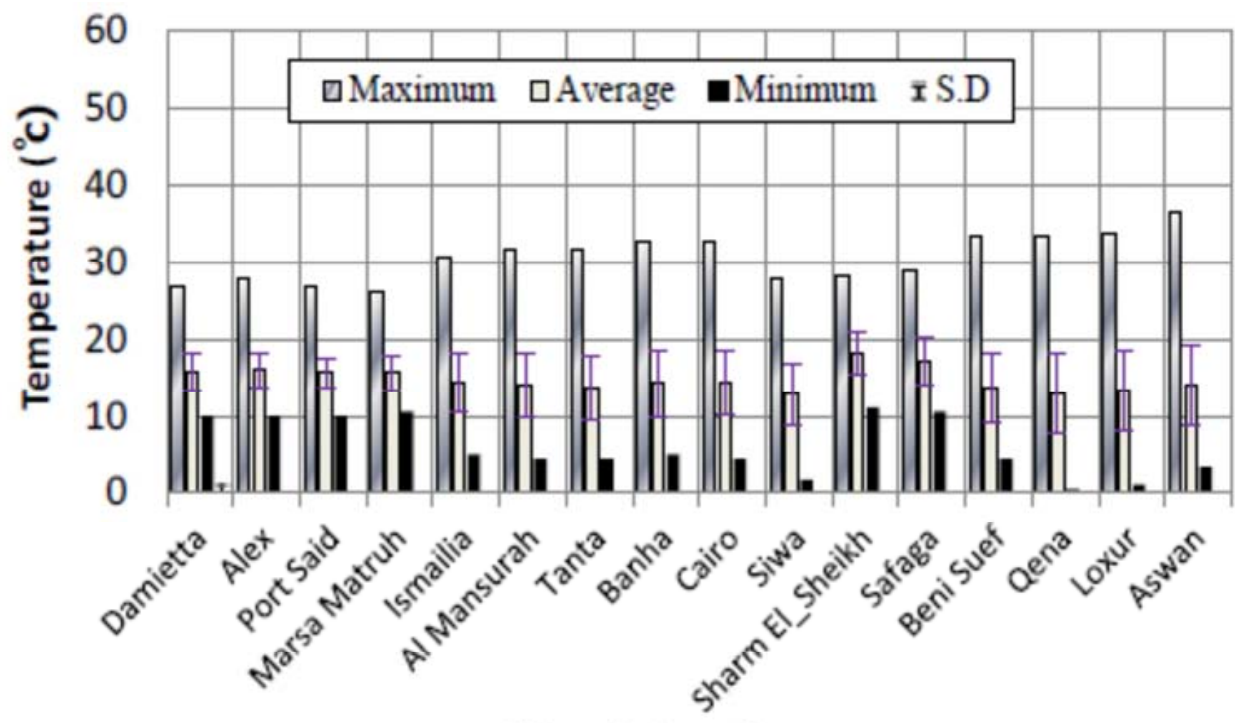

Climatic Location

Figure 1. Air temperatures during January in Egypt [24]. 


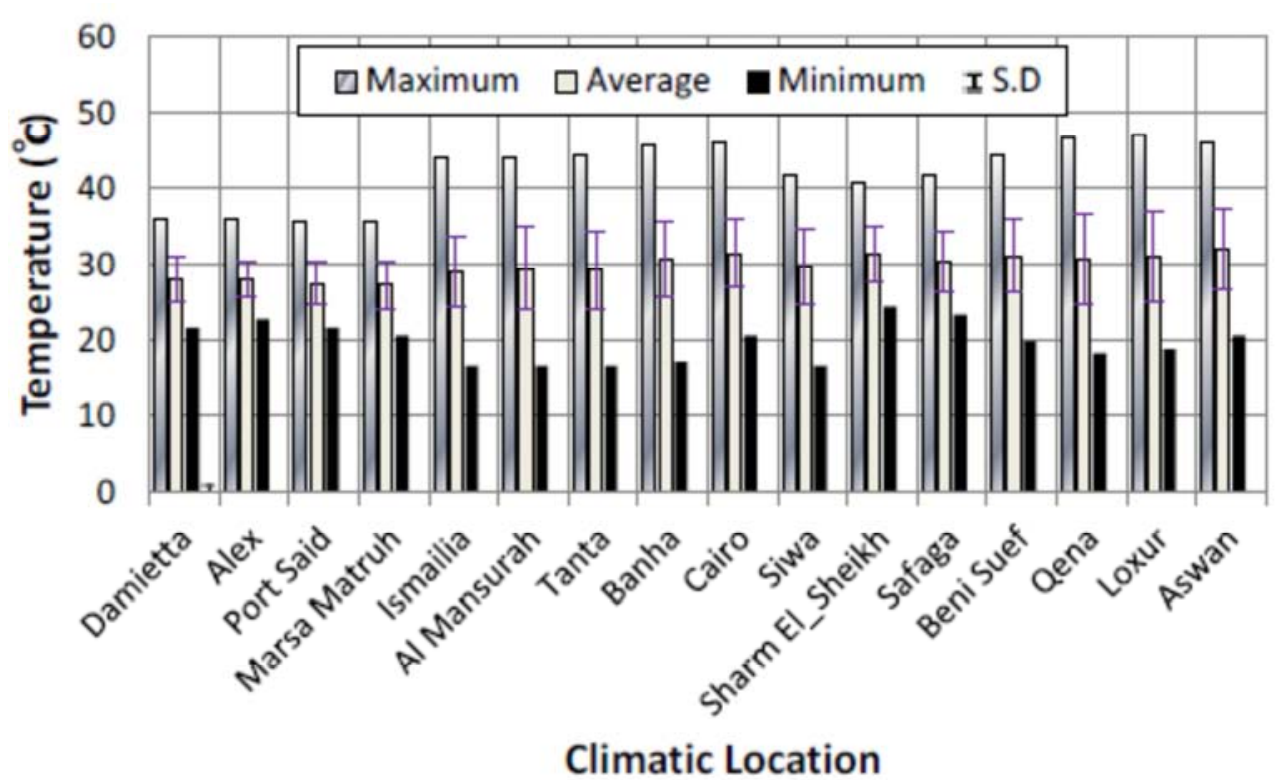

Figure 2. Air temperatures during August in Egypt [24].

\subsection{Pavement Temperature Prediction}

To account for the effects of temperature on flexible pavement behavior, the internal temperature of the asphalt layers must be known. The temperature can be measured directly by drilling holes into the pavement, but the procedure is time-consuming and multiple holes are needed to capture the temperature gradient. Temperature estimates based on correlations with externally measurable variables are preferable and, in fact, are the only source of design estimates for pavements that have not yet been constructed [2]. Numerous procedures and relationships have been developed to estimate pavement temperatures from climatic data. Some are based on heat-flow theory and are calibrated by using field data, whereas others are based solely on empirical data. Many of the relationships that have been developed are based on regional data, and their usefulness in other climates is questionable. According to YuanXun et al. (2011) [25], the surface temperature of asphalt concrete pavement is almost synchronous changes according to air temperature. With the increasing of pavement depth, the fluctuate lag of pavement temperature to air temperature rises and the amplitude drops off gradually. Moreover, with the increase of pavement depth, the change speed of temperature drops off gradually. Using regression formulas developed by Mohammad et al. (2014) [26], pavement temperature at a depth of $20 \mathrm{~mm}$ can be predicted using air temperature. Formula 7 represents the relationship between the minimum air temperature and the corresponding pavement temperature. Formula 8 represents the relationship between the maximum air temperature and the corresponding pavement temperature. Based on these regression formulas, the pavement temperature in this study was arranged between $5^{\circ} \mathrm{C}$ to $50^{\circ} \mathrm{C}$. Therefore, different asphalt layers' moduli in Egypt were considered to represent different climatic conditions from the greatest stiffness during winter to the weakest stiffness during summer.

$$
\begin{aligned}
& \text { Tpav }=1.2538^{*}\left(\text { Tair }_{\min }\right)+3.8505 \mathrm{R}^{2}=0.9612 \\
& \text { Tpav }^{2}=1.0725^{*}\left(\text { Tair }_{\max }\right)+0.0176 \mathrm{R}^{2}=0.9956
\end{aligned}
$$

\section{Results and Discussion}

\subsection{Deterioration Rates Under Temperature Change}

Figures 3 and 4 illustrate the vertical deflection and vertical strain respectively on the pavement surface from the load center up to a horizontal distance of 60 inch under different pavement temperatures $\left(5^{\circ} \mathrm{C}\right.$ to $\left.50^{\circ} \mathrm{C}\right)$ and for sections 1,4 and 7 to clarify the influence of temperatures and pavement section characteristics on the pavement surface performance. It is clearly noted that the surface deflection (rutting) and strain increase by increasing pavement temperature where this effect obviously decreases along with the horizontal distance especially after a distance of $30 \mathrm{inch}$. Moreover, the thinner and higher stiffness pavement section (sec.1) provides lower surface deflection and strain under various pavement temperatures. On the other hand, the temperature effect becomes more obvious at thicker and lower stiffness pavement section (sec.7). It is clarified that the increasing of pavement layers stiffness is more important characteristic than layers thickness in reducing deterioration rates and so improving the pavement surface performance under different temperatures.

Figures 5 and 6 show the vertical deflection and stress through pavement layers under load center at different pavement temperatures for sections 1,4 and 7 . It is illustrated that the deflection and stress decrease by increasing pavement depth and increase by increasing pavement temperature. Besides that, the thinner and higher stiffness pavement section (sec.1) provides lower deflection inside layers while provides higher stress at the same depth. It can be said that the increasing of pavement stiffness is more effective 
characteristic than thickness in reducing deflection while increasing of pavement thickness is more obvious factor in reducing stress through layers under different temperatures.

\subsection{Pavement Life and Damage Under Temperature Variation}

To evaluate the life of asphalt pavement affected by temperature change and solve the problem of an inaccurate estimation of fatigue and rutting damage by adopting a single fixed temperature, the impact of different temperatures on pavement rutting and fatigue lives is analyzed in this research. Figures 7 and 8 illustrate the horizontal tensile strain on the bottom of the asphalt layer and the vertical compressive strain on the surface of subgrade respectively. Moreover, Figure 9 shows pavement fatigue life (Nf) and rutting life (Nr) under temperature change for sections 1,4 and 7 . The both strains clearly increase with pavement temperature where the thinner and higher stiffness section (sec.1) provides higher tensile strain at low temperatures and lower tensile strain at high temperatures compared with other sections. Thus, it can be concluded that increasing the pavement layers stiffness (such as sec.1) is more effective in reducing tensile strain and thence increasing pavement fatigue life at higher temperatures $\left(23^{\circ} \mathrm{C}-50^{\circ} \mathrm{C}\right)$ while increasing the layers thickness (such as sec.7) is more effective at lower temperatures $\left(5^{\circ} \mathrm{C}-23^{\circ} \mathrm{C}\right)$. For compressive strain, increasing of pavement layers thickness is more influential characteristic than stiffness in reducing it and hence increasing pavement rutting life at all studied temperatures.

The pavement design life is the minimum number of load repetitions required to cause either fatigue or rutting failure. From Figure 9 that illustrates the both pavement lives, the pavement design life is governed by rutting failure for all studied temperatures and pavement sections. Moreover, both lives decrease with increasing pavement temperature unless the fatigue life of thinner and higher stiffness pavement section (sec.1) which increases by increasing temperature. This result clarifies the importance of layers stiffness on increasing pavement fatigue failures at higher temperatures.

Figure 10 illustrates the corresponding cumulative damage factor for sections 1,4 and 7 . The damage effect increases gradually with increasing temperatures, while it decreases with increasing layers thickness. Generally, it can be noted that the increasing of layers thickness is more effective than layers stiffness in increasing both pavement lives and decreasing damage factor where the both lives getting closer to degree of congruence at thicker and lower stiffness section (sec. 7).

\subsection{Suitable Pavement Cross Section Under Temperature Change}

To determine the most influential factor (layers stiffness or thickness) and select the suitable pavement cross section that resists the harmful effect of temperature change on pavement performance, the maximum surface deflection (rutting), pavement life, cumulative damage, and pavement design life period are investigated within seven pavement cross sections varying from thinner section of higher stiffness to thicker section of lower stiffness.

As shown in Figure 11 that illustrate the maximum deflection under load impact point, the optimal pavement section that shows the lowest deflection is the thinner and higher stiffness one (sec.1). Because temperature varies significantly across Egypt especially from north to south as well as east to west, the surface deflection and hence rutting is significantly affected by the climatic location where as the temperature increases, the rutting also increases. Thus, Egypt can be divided into three environmental locations (north, middle, and south) according to temperatures distribution. The northern part has mild climate and thus low rutting and low cumulative damage, the middle part has moderate climate and thus moderate rutting and moderate cumulative damage, while the south part has a very hot climate and thus high rutting and high cumulative damage.

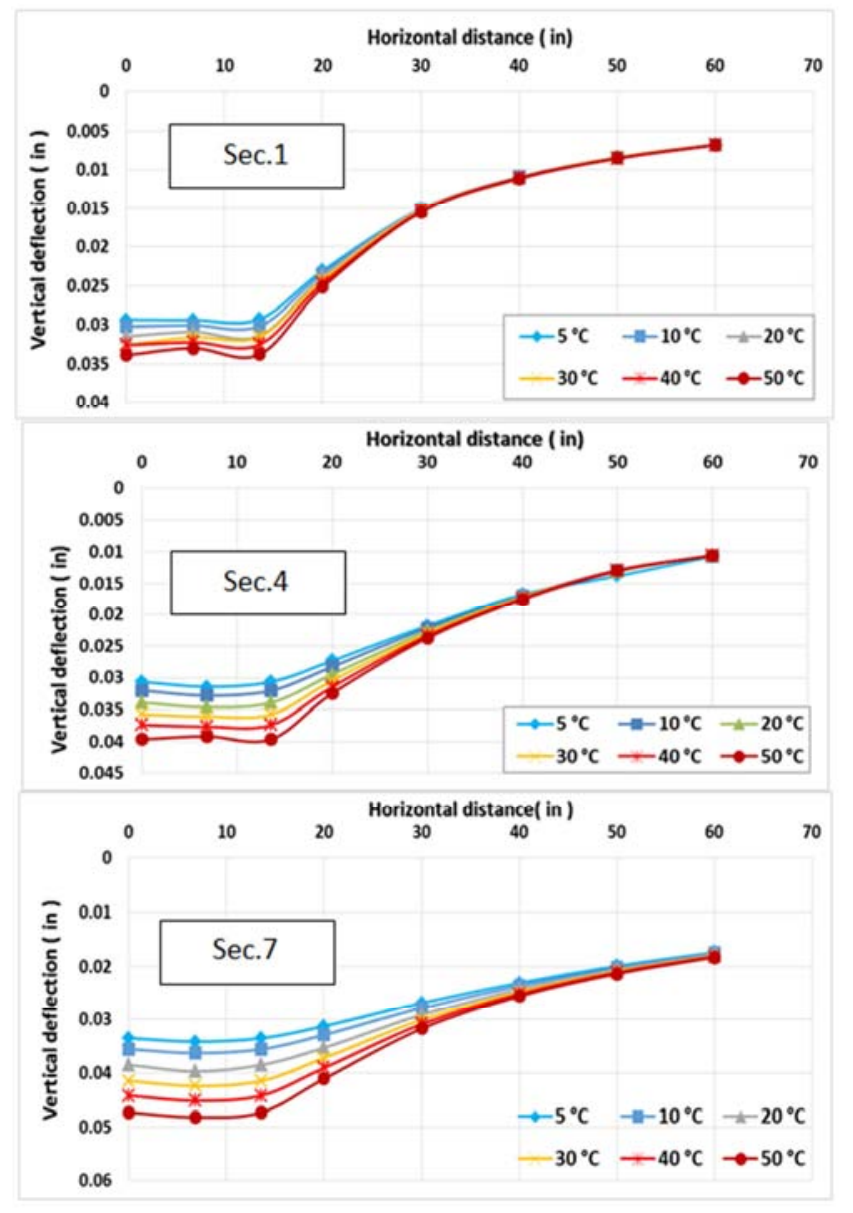

Figure 3. Vertical deflection on pavement surface under temperature change.

Figure 11 shows that the predicted surface deflections are very similar for the different sections at low temperatures (northern part of Egypt).

Figure 12 illustrates pavement fatigue and rutting lives. It can be noted that the layers thickness is more important than layers stiffness in increasing rutting life at all pavement temperatures. There is little variation in the predicted rutting 
lives at high temperature (south part of Egypt) from thinner pavement section of higher stiffness to thicker one of lower stiffness. For fatigue life, it increases with increasing pavement layers thickness up to temperature of about $23^{\circ} \mathrm{C}$.

After that temperature up to $50^{\circ} \mathrm{C}$, the sections are arranged in reverse where the fatigue life increases with increasing layers stiffness. Thus, the optimal pavement section that shows higher fatigue life up to temperature of $23^{\circ} \mathrm{C}$ and higher rutting life at all studied temperatures is the thicker and lower stiffness one (sec.7). While the thinner and higher stiffness section (sec.7) is optimal one for fatigue lives at temperature range $\left(23^{\circ} \mathrm{C}-50^{\circ} \mathrm{C}\right)$.

As illustrated in Figure 13, the minimum cumulative damage factor is achieved at thicker and lower stiffness sections such as (secs.5, 6 and 7) all studied temperatures. Section 5 provides the lowest damage may be due to achieving a balance between thickness and stiffness of pavement layers thus it is the optimal section in this point.

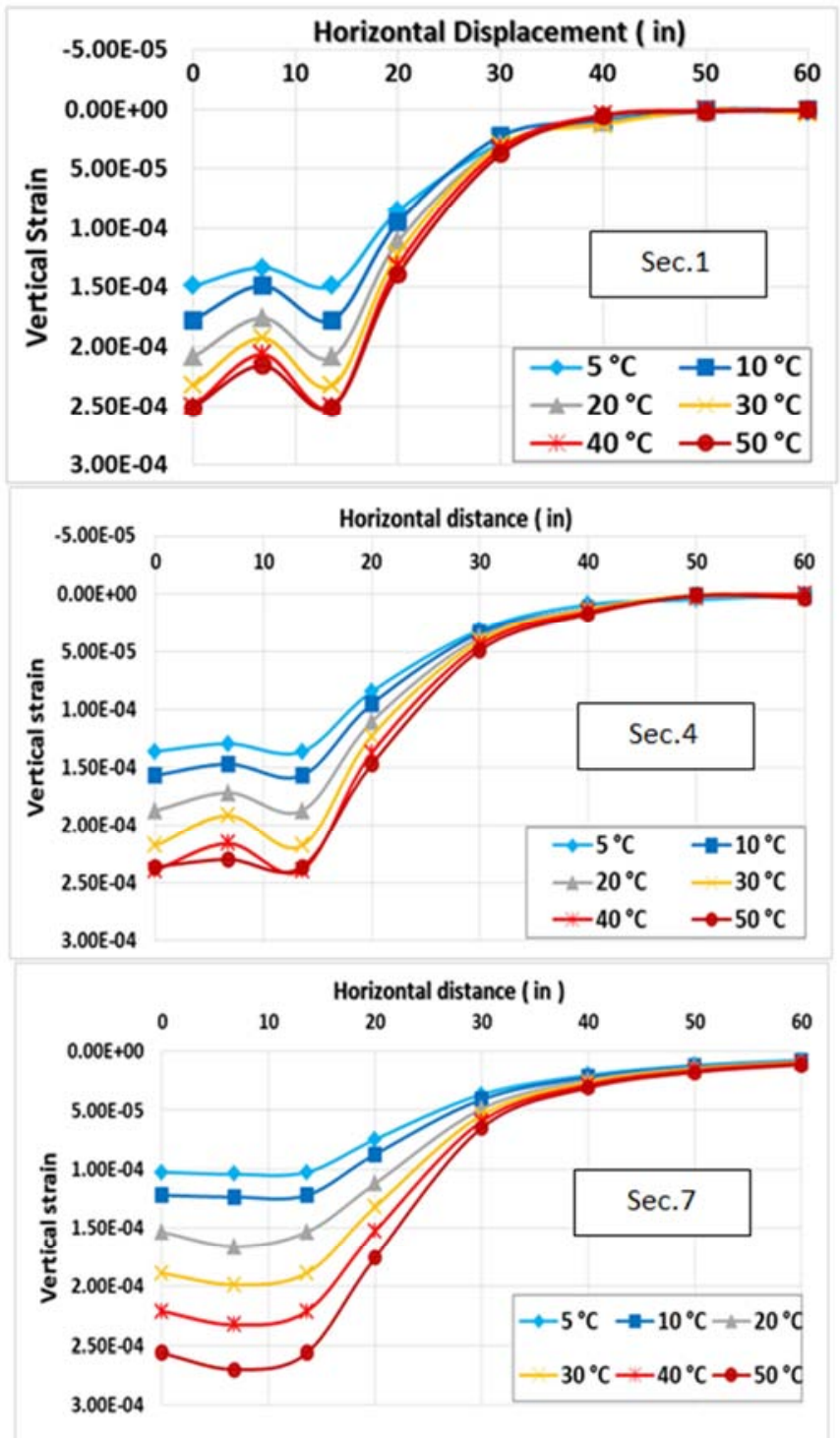

Figure 4. Vertical strain on pavement surface under temperature change.

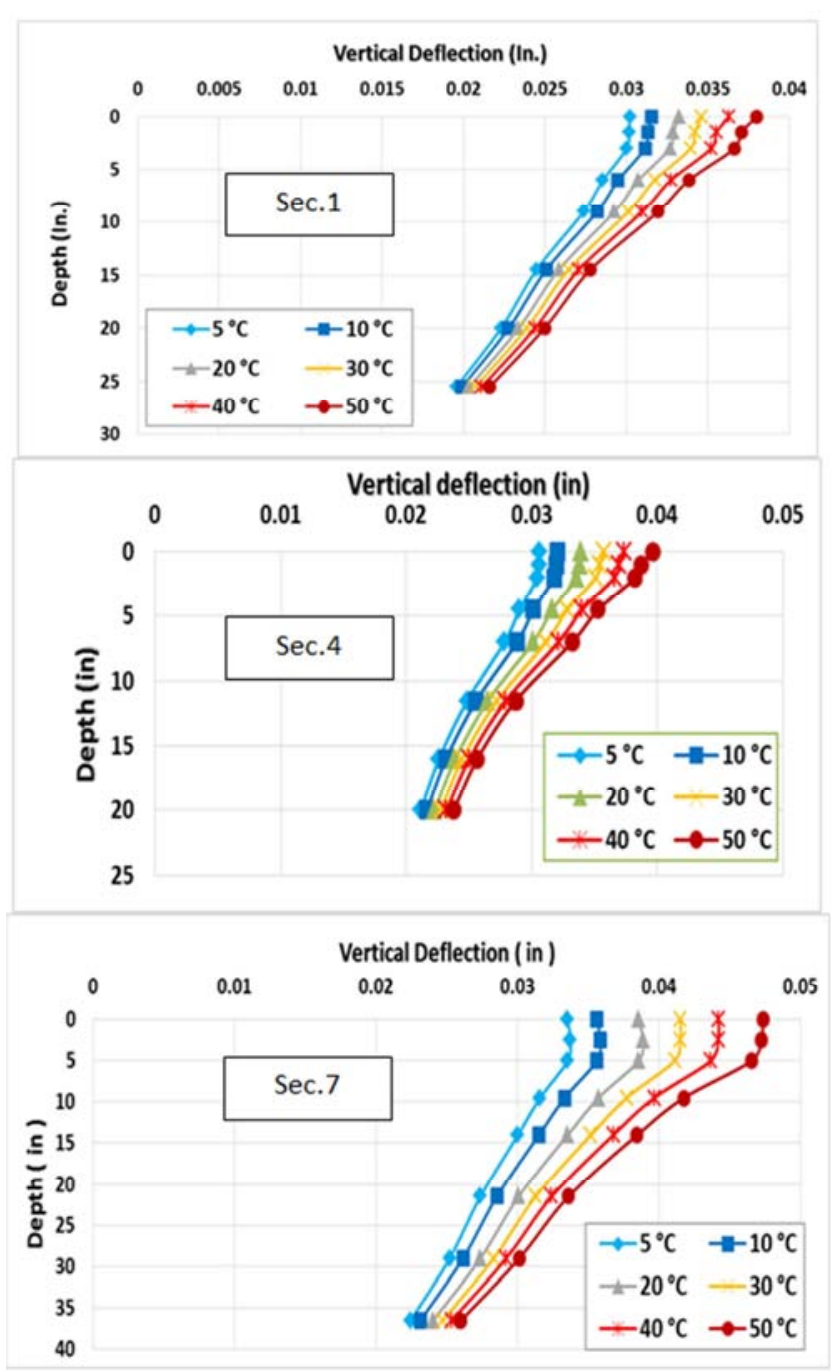

Figure 5. Vertical deflection in pavement layers under temperature change.

The design life period has been estimated based on mechanistic-empirical method and using field survey results that carried out at two rest- stations located on Cairo-Suez road and Cairo-Alexandria desert road [20]. From Figure 14, the thicker and lower stiffness sections (such as secs.7, 6 and 5) are the optimal sections in providing longer design life especially at lower temperatures $\left(5^{\circ} \mathrm{C}\right)$ as in northern part of Egypt. After that the life period decreases dramatically with temperature increasing up to about $20^{\circ} \mathrm{C}$ as in middle part of Egypt. More temperature than $20^{\circ} \mathrm{C}$, the design pavement lives slightly decrease up to $50^{\circ} \mathrm{C}$ as in south part of Egypt. For thinner and higher stiffness sections (such as secs.1, 2, 3 and 4), the temperature increase hasn't any obvious effect on pavement life period where the predicted life periods are very similar for all temperatures. This may be because sections 1 to 4 provide little variation in rutting life (as shown in Figure 12) that used in calculating life period under temperature change. 

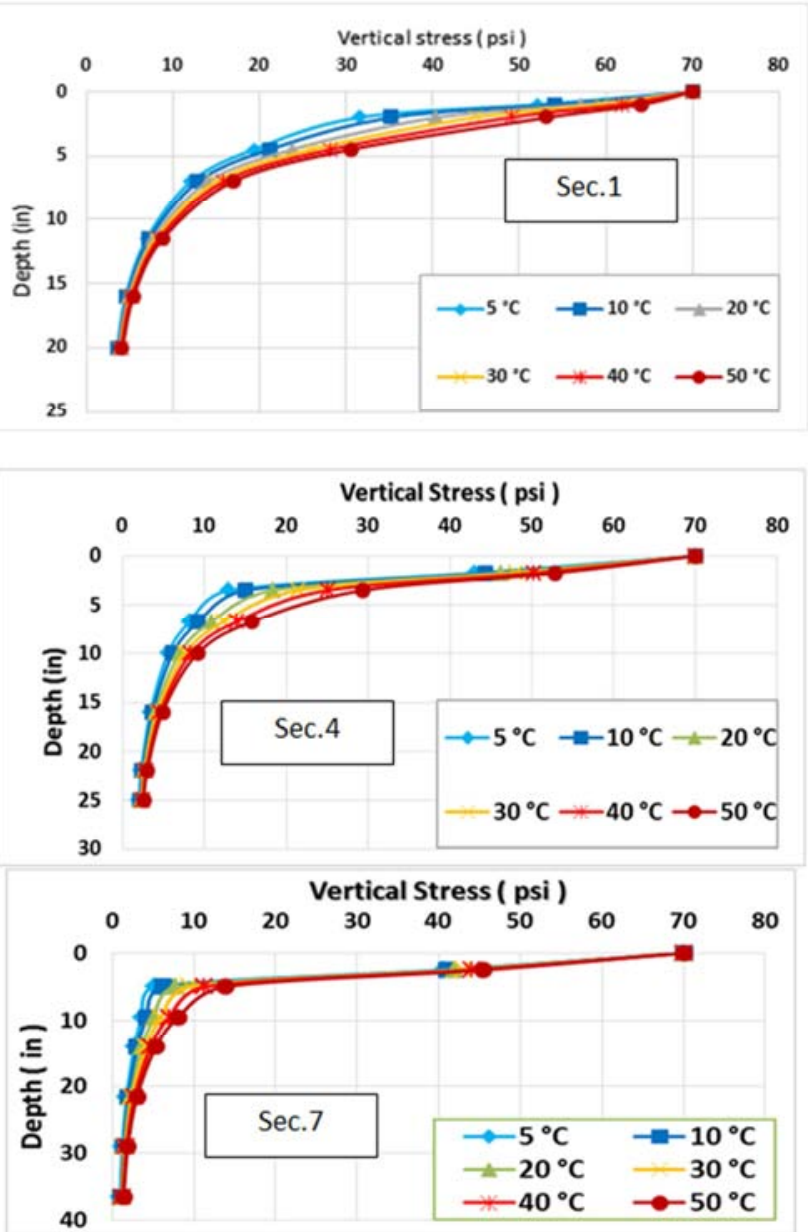

Figure 6. Vertical stress in pavement layers under temperature change.

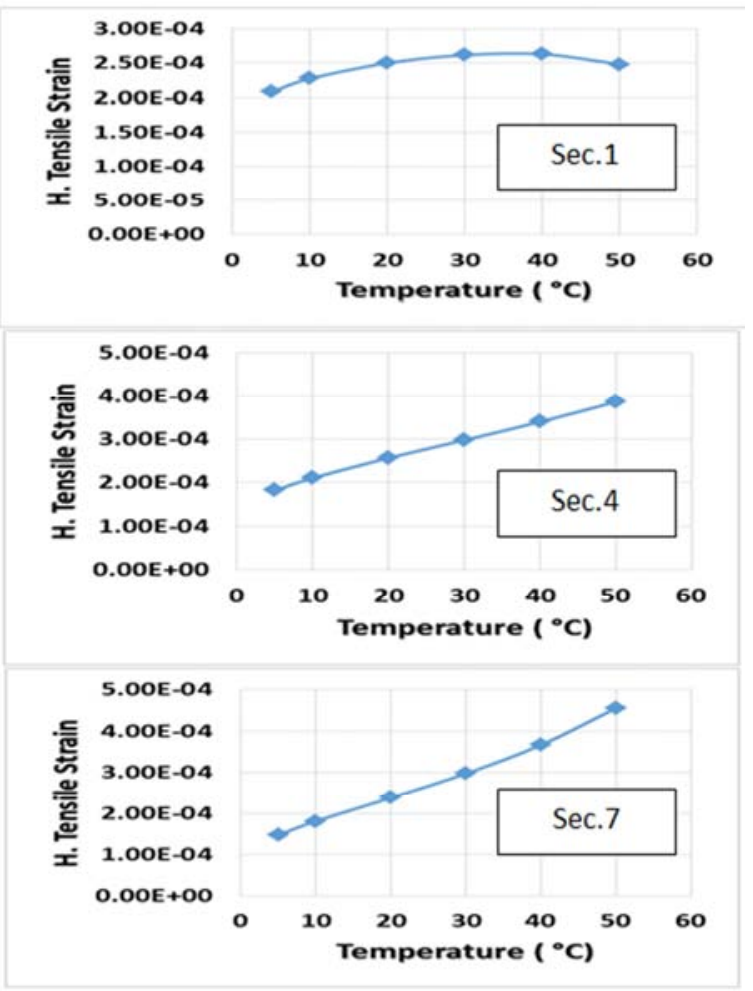

Figure 7. Horizontal tensile strain under temperature change.

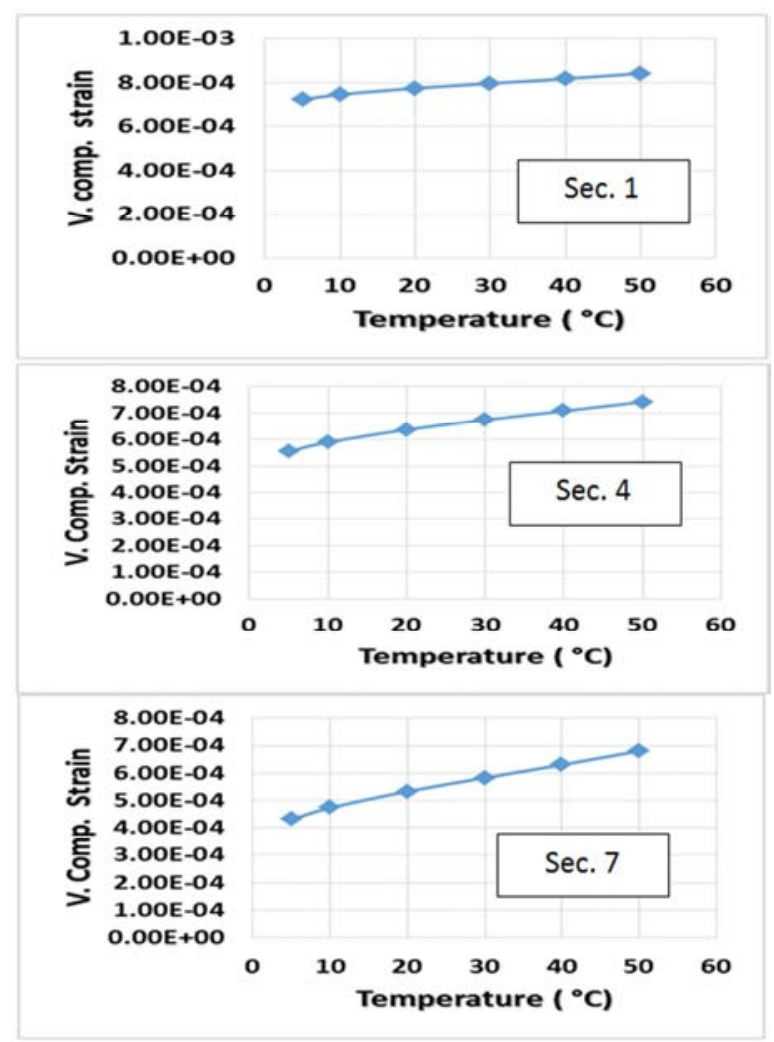

Figure 8. Vertical compression strain under temperature change.

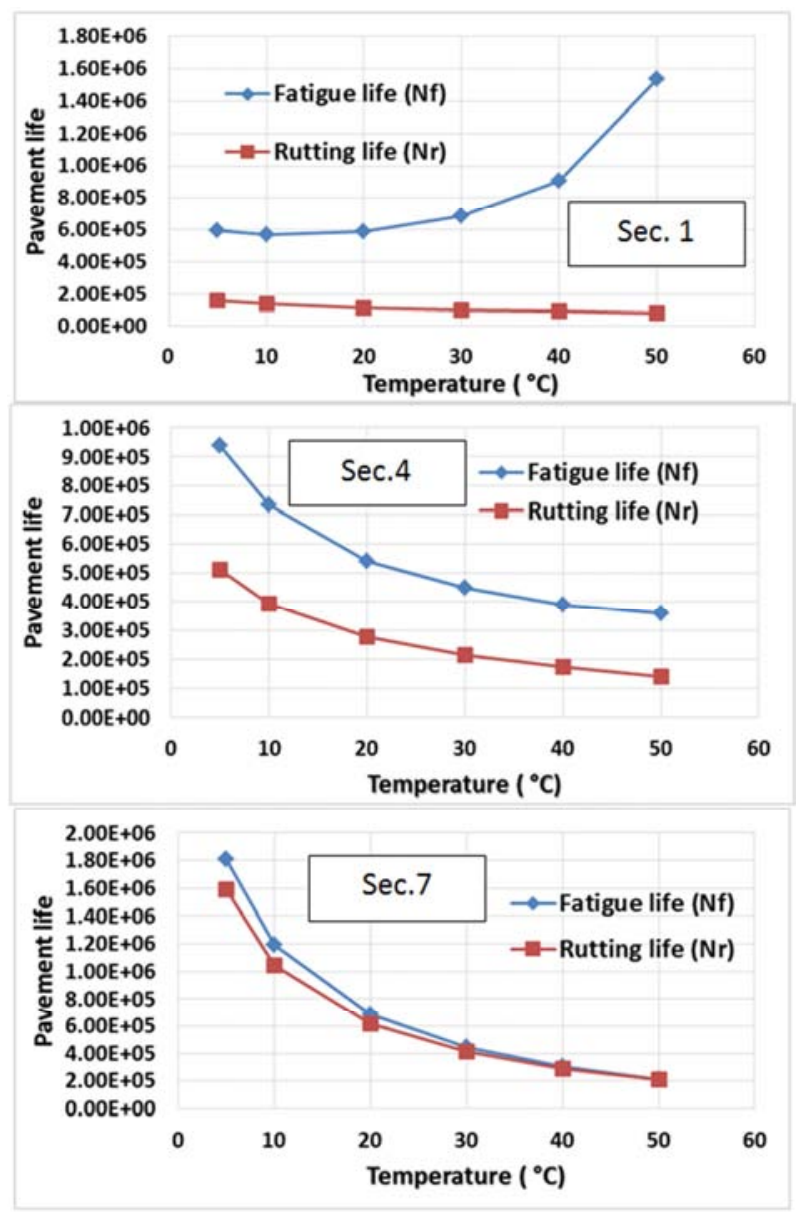

Figure 9. Rutting and fatigue lives under temperature change. 


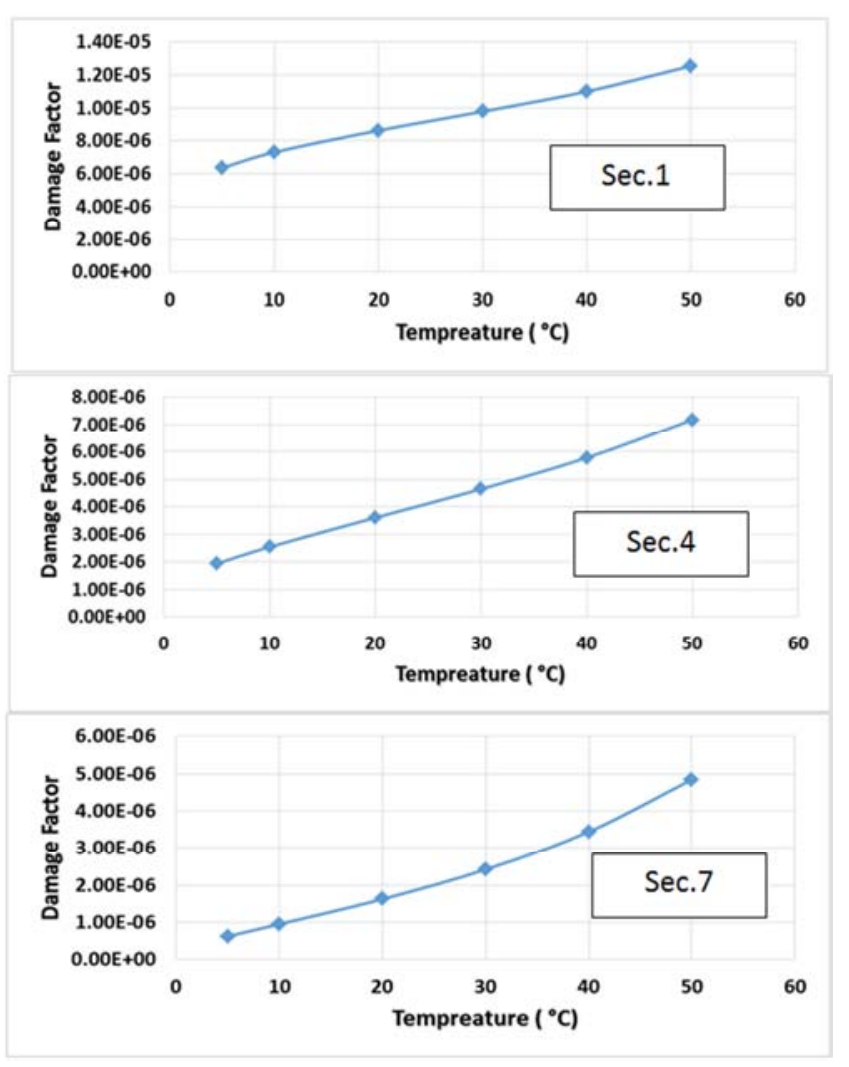

Figure10. Cumulative damage factor under temperature change.

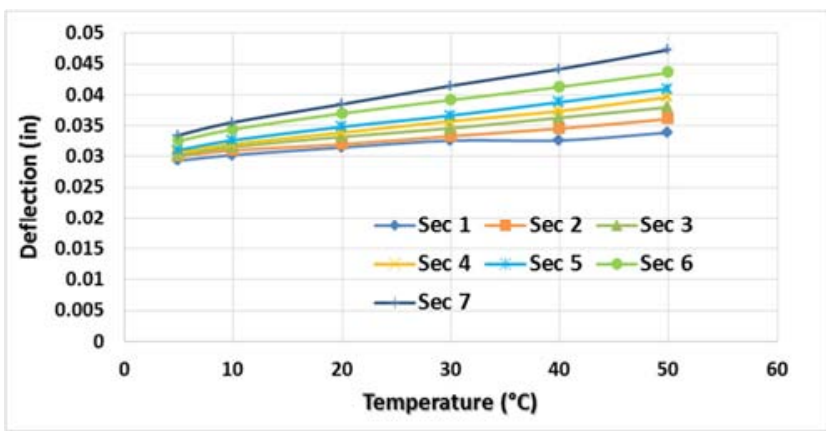

Figure 11. Maximum surface deflection for all pavement sections.

\section{Summary and Conclusions}

This study was carried out to investigate the effect of

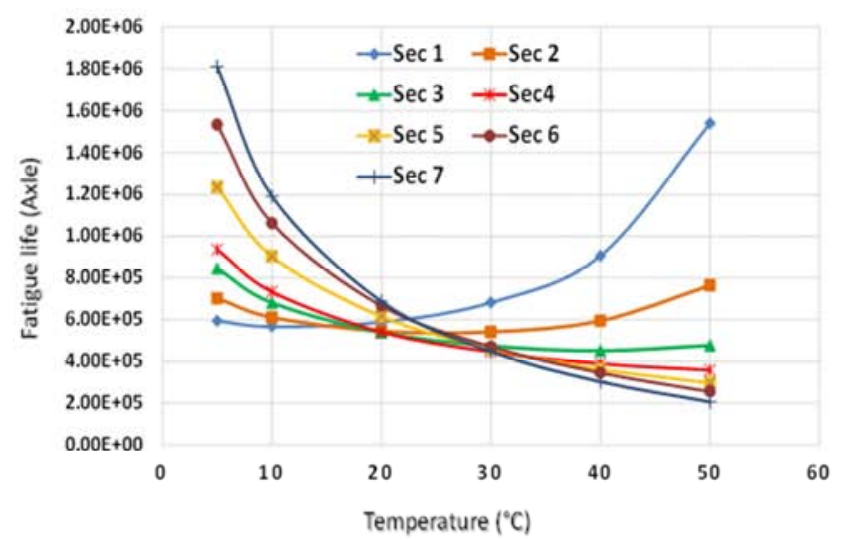

variation temperature in Egypt on the predicted pavement damage ratio and life as well as the changes in pavement performance measured in terms of stress, strain and deflection distributions on the pavement surface and through layers. According to the methodology and analysis of results for this study, the following conclusions were drawn:

1. Pavement performance was significantly affected by the change in the temperature. As expected, the predicted deflection (rutting of the asphalt layer), vertical strain and stress increased on pavement surface as well as through layers by increasing pavement temperature.

2. Increasing of pavement stiffness (such as sec.1) was more effective characteristic than layers thickness in reducing the surface and internal deflection and strain and in increasing pavement fatigue life at higher temperatures $\left(23^{\circ} \mathrm{C}-50^{\circ} \mathrm{C}\right)$. While, increasing of pavement thickness (such as sec.7) was more influential factor in reducing stress through layers under temperatures variation, increasing pavement rutting life at all temperatures and in increasing fatigue life at lower temperatures $\left(5^{\circ} \mathrm{C}-23^{\circ} \mathrm{C}\right)$.

3. The pavement design life was governed by rutting failure at all temperature variations where the both lives getting closer to degree of congruence at thicker and lower stiffness section. The damage effect increased gradually with increasing temperatures and decreased with increasing layers thickness at the expense of stiffness.

4. The thicker and lower stiffness sections (such as secs.7, 6 and 5) were the optimal sections in providing longer design life period especially at the lowest temperatures $\left(5^{\circ} \mathrm{C}\right)$ as in northern part of Egypt. After that the life period decreased dramatically with temperature increasing up to about $20^{\circ} \mathrm{C}$ as in middle part of Egypt. More temperature than $20^{\circ} \mathrm{C}$, the design pavement lives slightly decreased up to $50^{\circ} \mathrm{C}$ as in south part of Egypt. For thinner and higher stiffness sections (such as secs.1, 2, 3 and 4), the temperature increase hadn't any obvious effect on pavement life period where the predicted life periods were very similar for all temperatures.

Figure 12. Fatigue and rutting lives for all pavement sections.

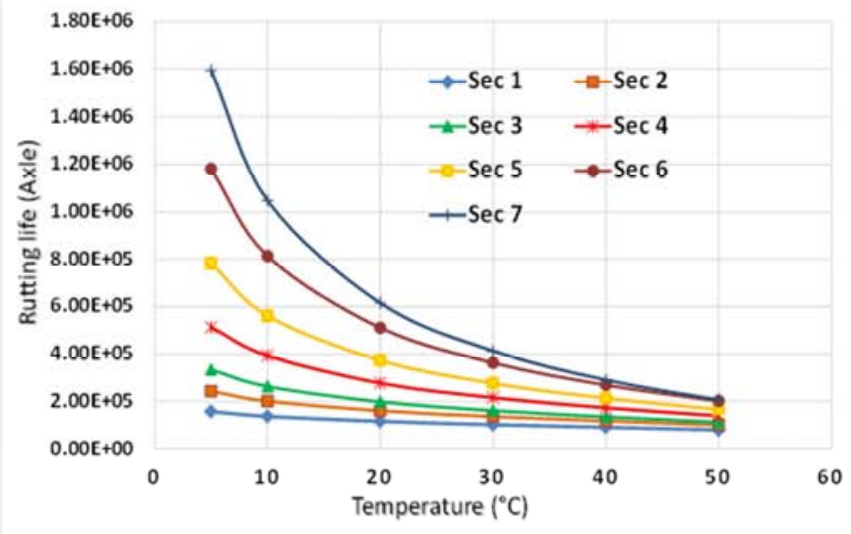




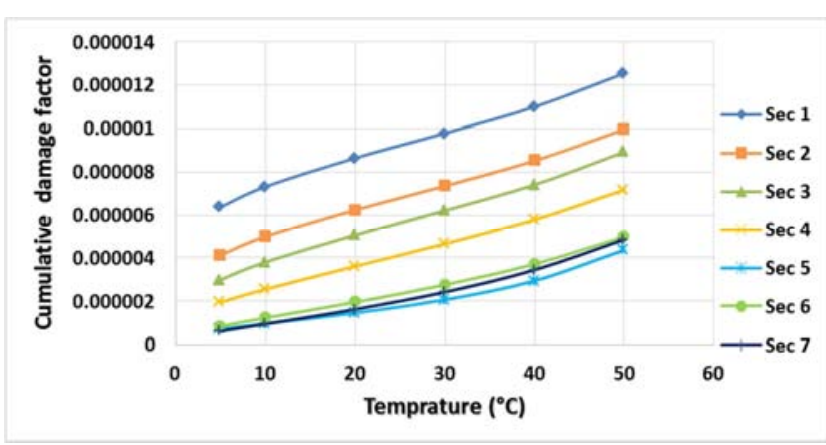

Figure 13. Cumulative damage factor for all pavement sections.

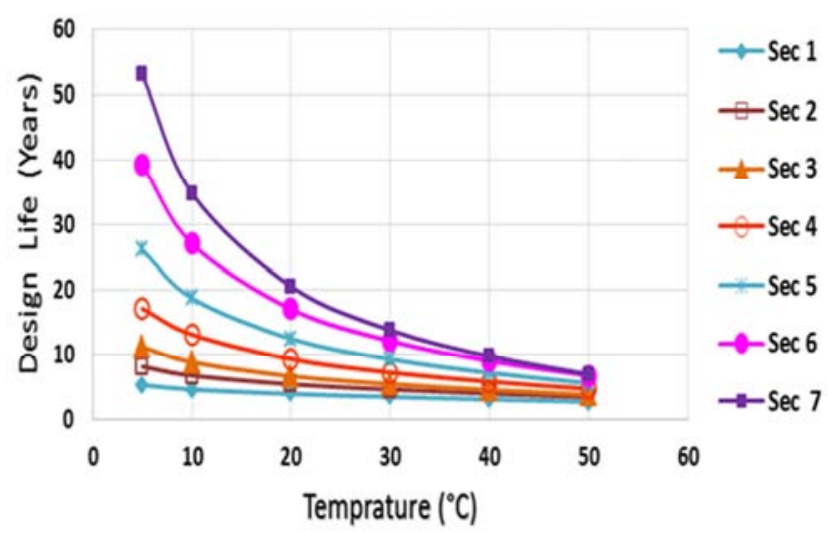

Figure 14. Pavement design life period for all pavement sections.

\section{References}

[1] Flavio, V. S. and Leandro, S. C., 2012. Effect of temperature on the mechanical response of thermo-viscoelastic asphalt pavements. Construction and Building Materials, 30, 574-582.

[2] Marshall, C., Meier, R. W., and Welsh, M., 2001. Seasonal temperature effects on flexible pavements in Tennessee. Transportation Research Board, No. 1764, Washington, D. C., 89-96.

[3] Gang, Z., 2003. Impacts of environmental factors on flexible pavements. Ph. D. thesis, University of Tennessee, Knoxville.

[4] Sascha, K. and Frohmut, W., 2013. Impact of surface temperature on fatigue damage in asphalt pavement. Journal of Highway and Transportation Research and Development, Vol. 7, No. 3, 1-6.

[5] Kang, H., Zheng, Y. and Cal, Y., 2007. Regression analysis of actual measurement of temperature field distribution rules of asphalt pavement. China Journal of Highway and Transport, 20 (6): $13-18$.

[6] Gang, Z., Eric, C., and Roger W., 2007. Environmental effects on the predicted service life of flexible pavements. Journal of Transportation Engineering, ASCE, Vol. 133, No. 1, 47-56.

[7] Li, Q., Mills, L., McNeil, S., and Attoh-Okine, N., 2012. Exploring the impact of climate change on pavement performance and design. Transportation Research Board 91st Annual Meeting, Paper No. 12-2096.

[8] Yaning, Q., Gerardo, W., Andrew, R. and Tony P., 2013. Examining the effects of climatic factors on flexible pavement performance and service life. Journal of the Transportation Research Board. Washington, D. C., No. 2349, DOI: 10. 3141/2349-12.

[9] Byram, D., Xiao, D. X., Wang, K. C. P. and Hall, K., 2012. Sensitivity analysis of climatic influence on MEPDG flexible pavement performance prediction. Transportation Research Board 91st Annual Meeting, Washington, D. C., 2012.

[10] Saha, J., Nassiri S., Bayat, A., and Soleymani, H., 2014. Evaluation of the effects of Canadian climate conditions on the MEPDG predictions for flexible pavement performance. International Journal of Pavement Engineering, 15 (5). 392-401.

[11] Antonio, R. G. and Maria, C., 2011. Analysis of the temperature influence on flexible pavement deflection. Construction and Building Materials, 25, 3530-3539.

[12] Fajing, Pan., Lei, W., Jinke, J. and Wang, J., 2015. A research review of flexible pavement temperature profile. International forum on energy, Environment Science and Materials (IFEESM), 724-727.

[13] Bayomy, F., El-Badawy, S., and Awed, A., 2012. Implementation of the MEPDG for flexible pavements in Idaho. (Report No. FHWA-ID-12-193). ITD Project RP 193, NIATT Project KLK557. National Institute for Advanced Transportation Technology, University of Idaho, Moscow, Idaho: U.S.

[14] Park, D., Buch, N., and Chatti, K., 2001. Effective layer temperature prediction model and temperature correction via falling weight deflectometer deflections. Transportation Research Record, Vol. 1764, Paper No. 01-0121, 97-112.

[15] American association of state highway officials, AASHTO, 1993. AASHTO guide for the design of pavement structures. Washington, D. C., 403.

[16] Abu El-Maaty, A., 2012. Fatigue and rutting lives in flexible pavement. Ain Shams Engineering Journal, 3, 367-374.

[17] Breakah, T., Williams, R., Herzmann, D., and Takle, E., 2011. Effects of using accurate climatic conditions for mechanistic-empirical pavement design. Journal of Transportation Engineering, 137 (1), pp. 84-90.

[18] Samad, E., 2011. Sensitivity analysis in flexible pavement performance using mechanistic empirical method. (Case study: Cirebon-Losari road segment, West Java). Civil Engineering Forum, Vol. 20, 12p.

[19] Egyptian Code of Practice for Urban and Rural Roads, ECP 2012.

[20] Abu El-Maaty, A., Yousry, A., 2013. Mechanistic-empirical study of sensitivity of truck tire pressure to asphalt pavement thickness in Egypt. Int. Journal of Engineering Research and Application, Vol. 3, Issue 5, pp. 1760-1771.

[21] Hsu, T. W., and Tseng, K. H., 1996. Effect of rest periods on fatigue response of asphalt concrete mixtures. Journal of Transportation Engineering, American Society of Civil Engineering, Vol. 122, No. 4, 316-322.

[22] Salehabadi, E. G., 2012. The linear elastic analysis of flexible pavement by the finite element method and theory of multiple-layers system. Switzerland Research Park Journal, Vol. 101, No. 9, 363-371. 
[23] Abdel-Motaleb, M. E., 2007. Impact of high pressure truck tires on pavement design in Egypt. Emirates Journal for Engineering Research, 12 (2), 65-73.

[24] Maha, A. E., Sherif, M. E. and El-Sayed, A. S., 2014. Development and impact of the Egyptian climatic conditions on flexible pavement performance. American Journal of Civil Engineering and Architecture, Vol. 2, No. 3, 115-121.

[25] YuanXun, Z., YingChun, C. and YaMin, Z., 2011. Study on temperature field of asphalt concrete pavement. Emerging Technologies for Material, Design, Rehabilitation, and Inspection of Roadway Pavements, Geotechnical Special Publication No. 218 C ASCE, 266-273.

[26] Mohammad, H. A. and Medhat, M. H., 2014. A mathematical model for the distribution of heat through pavement layers in Makkah roads. Journal of King Saud University - Engineering Sciences, 26, 41-48.

\section{Biography}

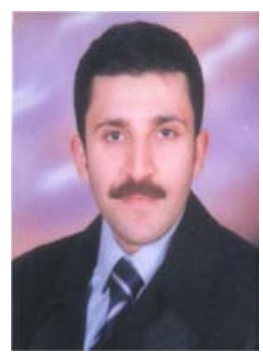

Ahmed Ebrahim Abu El-Maaty is an Associate Professor in department of Civil Engineering, Menoufia University, Egypt. He received his $\mathrm{Ph}$. D. in Egypt 2007. He has many scientific researches published in international journals. His fields of interest include highway structure design and pavement management, consistency of soil reinforcement, flexible and concrete pavement, finite elements analysis, fundamentals of geotechnical engineering and traffic performance analysis. 